EPiC Series in Education Science
Volume 2, 2019, Pages 40-48
$\begin{gathered}\text { Proceedings of Learning Innova- } \\ \text { tions and Quality (LINQ) 2019 }\end{gathered}$

\title{
A Holistic Pedagogical Model for STEM education in schools: Its Design and Evaluation through Mixed Methods Research with Surveys and Interviews
}

\author{
Christian M. Stracke ${ }^{1}$, Guido van Dijk ${ }^{2}$, Jan Fasen ${ }^{2}$, Fred Lisdat ${ }^{3}$, \\ Anita Wesolowski ${ }^{3}$, Wim Simoens ${ }^{4}$, Jo Desutter ${ }^{4}$, Joke Lippens ${ }^{4}$, \\ Alma Rimkevič $\dot{e}^{5}$, Jurate Daneniene ${ }^{6}$, Vaiva Kelmelyte ${ }^{6}$, Rui Baltazar ${ }^{7}$, \\ António Barreiros ${ }^{7}$, Alcino Pascoal ${ }^{8}$, Mario Spatafora ${ }^{9}$, Ana Maria Cotovanu ${ }^{9}$, \\ and Alessia Spatafora ${ }^{9}$ \\ ${ }^{1}$ Open University Netherlands, Heerlen, The Netherlands \\ ${ }^{2}$ Agora School, Roermond, The Netherlands \\ ${ }^{3}$ Technical University of Applied Science Wildau, Germany \\ ${ }^{4}$ Eekhout Academy, Kortrijk, Belgium \\ ${ }^{5}$ Kauno Simono Daukanto Progimnazija School, Lithuania \\ ${ }^{6}$ Kaunas Science and Technology Park, Lithuania \\ ${ }^{7}$ Group of Schools Emido Navarro, Almada, Portugal \\ ${ }^{8}$ Universidade Nova de Lisboa, Caparica, Portugal \\ ${ }^{9}$ Effebi Association, Rome, Italy \\ Christian.Strackedou.nl
}

\begin{abstract}
This article discusses how to innovate school education. It provides a holistic framework for pupil-centered learning processes developed by an international research consortium. It is based on the findings from a literature review, three online survey and semi-structured interviews with participation of teachers $(n=211)$, headmasters $(n=21)$ and learners $(n=337)$ from more than ten countries. The research results are used for a teacher training programme and an online course that the international research consortium is currently designing and implementing. This article presents the holistic pedagogical model Learn STEM as the first outcome of the Mixed Methods Research conducted by the international research consortium.
\end{abstract}




\section{Introduction}

Learners need to build and continuously improve strong competences and abilities related to science, technologies, engineering and mathematics (STEM) in order to be competitive in the $21^{\text {st }}$ century work environment (Stracke, 2014, 2019; Weinert, 2001). The demands on future pupils, citizens and workers are changing and increasing (Organisation for Economic Co-operation and Development, 2016; Stracke, 2011; World Bank, 2016). Thus, the development of profound knowledge, skills and competences in team work, rational thinking and investigative and creative work which learners can use in all areas of life, is essential (Dewey, 1966; European Commission, 2007; Piaget, 1953; Rousseau, 1968; Stracke, 2012a, 2012b; Vygotsky, 1988; Westera, 2001). An international research team was established addressing this need to improve the quality and efficiency of STEM education in schools. The research team conducted Mixed Methods research that facilitated the development of a holistic pedagogical model for learning STEM as well as of a teacher training programme for its introduction and implementation. This article presents briefly key findings from the Mixed Methods research (section 2) and provides an overview of the holistic pedagogical model (section 3). It concludes with an outlook on next future activities such as the teacher training programme and the online course as well as on further research demands (section 4).

\section{Mixed Methods research}

The international research team started the Mixed Methods research with an extensive and indepth literature review on the current status of STEM education in schools and needs for changes and improvements (submitted to journal, currently under review). The findings were quite homogenous: a huge demand for innovative STEM education and teacher training as well as for further research on learner-centered and competence-based pedagogies (see e.g., Harlen, 2015; Organisation for Economic Co-operation and Development, 2016; Vasquez, 2014; World Bank, 2016). Therefore, the research team has designed a three-year Mixed Methods research plan combining surveys and interviews. The overall objective was to develop a holistic pedagogical model for innovating STEM education in schools informed by the findings from the literature review, the conducted surveys and interviews.

First, the pedagogical model was developed in iterative improvement cycles leading to 35 interim versions before a final draft was published (Stracke et al., 2019). The interim versions were already presented and discussed at international conferences so that the final draft already included feedback from external researchers, teachers and headmasters. For further improvements and validation, three surveys on STEM education were elaborated by all research partners: for teachers, for headmasters and for learners. Next to demographic questions, the question items for all three target groups were clustered and formulated in similar ways that they can be compared. The three surveys were implemented and published online by the coordinator of the research team and accessible for all interested persons worldwide. The surveys opened on Friday, 22nd of February 2019 and closed on Friday, 14th of June 2019 after 16 weeks.

The following Figure 1 presents the numbers of survey participants, their countries for each of the three surveys. 


\begin{tabular}{|l|c|c|c|c|}
\hline & Teachers & Headmasters & Learners & Sum \\
\hline The Netherlands & 11 & 0 & 118 & 129 \\
\hline Lithuania & 7 & 3 & 24 & 34 \\
\hline Italy & 18 & 1 & 68 & 87 \\
\hline Germany & 19 & 0 & 34 & 53 \\
\hline Portugal & 114 & 10 & 76 & 200 \\
\hline Belgium & 27 & 7 & 14 & 48 \\
\hline Other countries & 15 & 0 & 3 & 18 \\
\hline TOTAL: & 211 & 21 & 337 & 578 \\
\hline
\end{tabular}

Figure 1: Participants in the three surveys on STEM education

In the following, first findings from the comparison of the results from the teachers' and headmasters' surveys are presented, the detailed analysis is currently underway.

An interesting result are the different answers by the teachers and headmasters on question 2.4: "STEM education within my school focuses too much on specialised and detailed topics" as presented in the following figures 2 and 3 :

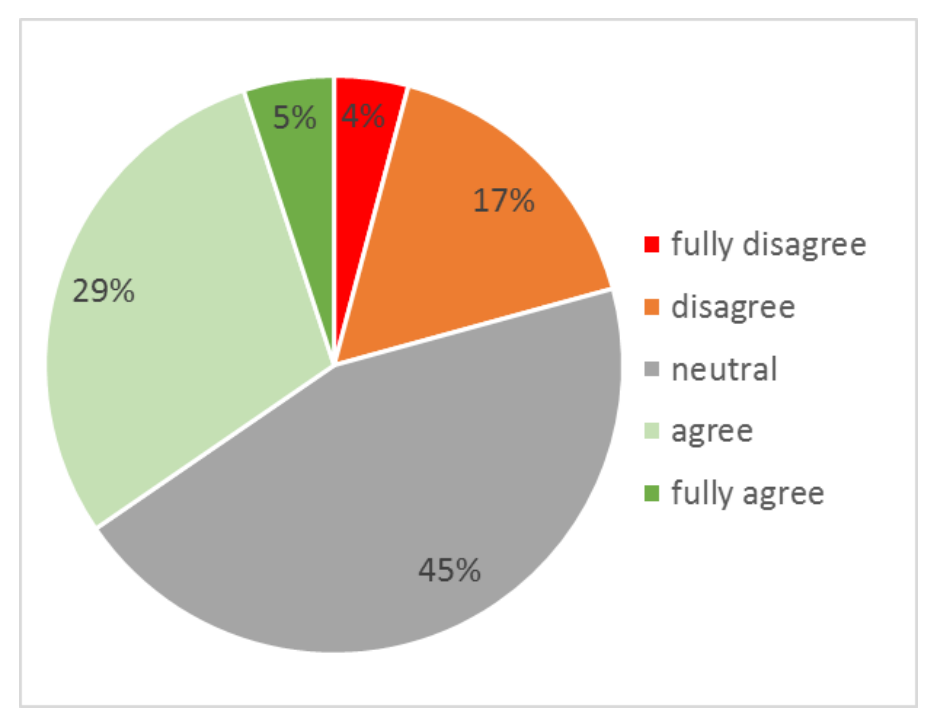

Figure 2: Answers from teachers on question 2-4 


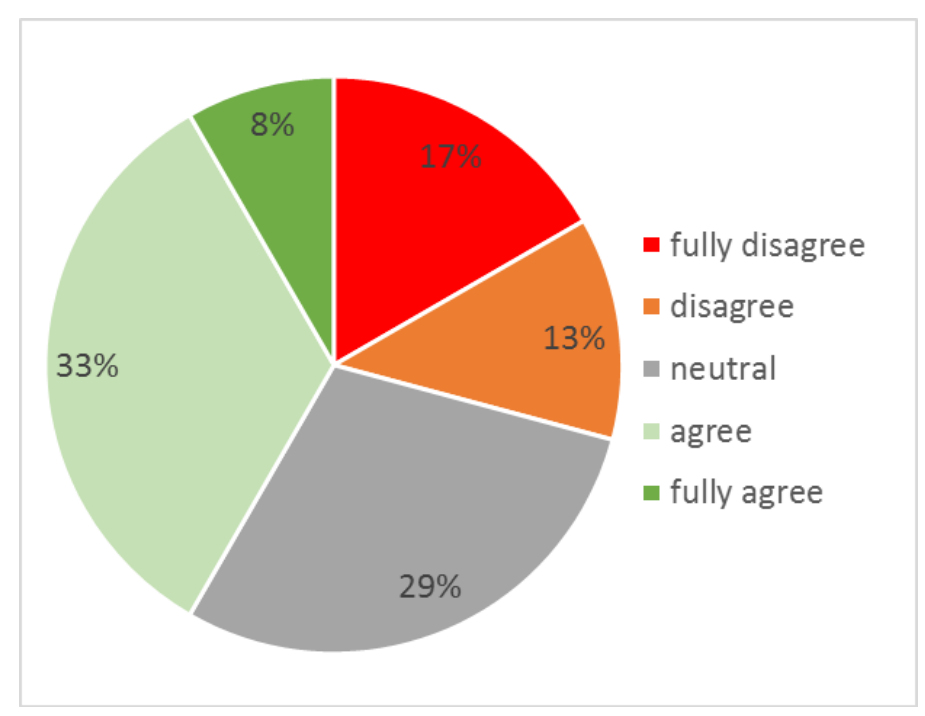

Figure 3: Answers from headmasters on question 2-4

It can be stated that both, teachers and headmasters, tend to confirm that the STEM education in their school is currently too much focused on specialised and detailed topics. However, the view of the headmasters is more positive than the teachers' perspective (17\% vs. $4 \%$ fully disagree) what could explain a slower change in STEM education in some schools due to lack of headmasters' support.

Related to the pedagogical model, the answers from teachers as well as from headmasters are very positive and both groups are appreciating highly its value: $74 \%$ of the participating teachers fully agreed or agreed that the Learn STEM Pedagogical Model is useful for enhancing the quality of school education and learners' STEM competences (fully disagree: 4, disagree: 0, neutral: 52, agree: 105 , fully agree: 56). And even $92 \%$ of the participating headmasters fully agreed or agreed that the Learn STEM Pedagogical Model is useful for enhancing the quality of school education and learners' STEM competences (fully disagree: 0 , disagree: 0 , neutral: 2 , agree: 10 , fully agree: 12 ).

Next to this overwhelming positive feedback, the teachers and headmasters provided some minor recommendations and proposals how to improve the pedagogical model in the open question at the end of the surveys: They will be integrated in the next version of the pedagogical model that will be briefly introduced in the following section. 


\section{The holistic Pedagogical Model Learn STEM}

The pedagogical model Learn STEM focuses on the learner who shall become the owner of their own learning processes. Thus, the role of teachers needs to change: teachers should facilitate such learning processes and act as coaches. However, teachers may also guide and supervise the learning process. Learn STEM can be combined with other approaches and methodologies to learn and teach STEM.

Learn STEM is based on educational theories and positions and focuses mainly on the following five characteristics of the learning process:

- Complex

- Process-oriented

- Holistic

- Practical

- Social

Learn STEM objectives comprise three elements: knowledge, skills and competences. Learners gain STEM knowledge and build STEM skills. Through reflection and

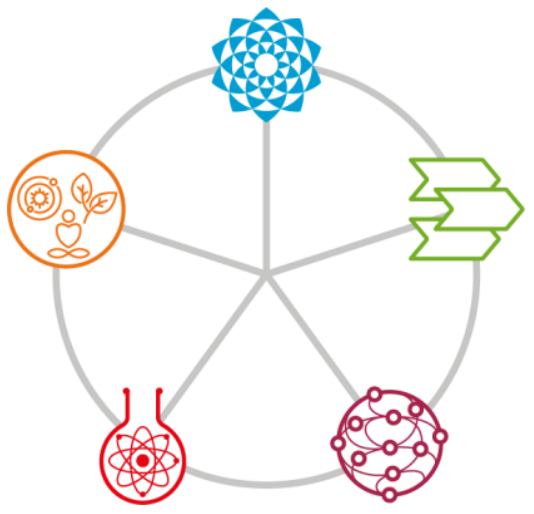
repeated training, they build STEM competences based on assimilation and accommodation. The learning process should be interdisciplinary and holistic. Learning is considered a process going through iterative improvement cycles. Here, the model allows flexibility since the teacher can act more as a coach or as a tutor depending on the situation in the respective educational system. Training modules can help to solidify acquired algorithms and knowledge and to support the learners to gain confidence in using them. Practical courses are valuable tools during the learning process as they allow to expand knowledge, but also to develop practical skills. Learners will use and demonstrate their obtained knowledge and skills in everyday life problems and successfully apply their developed competences in new situations. Learn STEM incorporates the complexity of STEM learning activities related to the various STEM disciplines as well as to the interrelation with other areas: Learn STEM connects the world of learners with our society and provides insights into the complex relations between STEM and society.

\subsection{Learn STEM is complex}

Learn STEM is complex in regards to the specificity of the covered disciplines. It is interdisciplinary as it connects the numerous subjects and underlines common principles and approaches.

STEM is a complex system incorporating specific characteristics and terms of the different fields. Thus, Learn STEM covers a variety of subjects, terminologies and scientific interrelations. Learn STEM aims to create profound

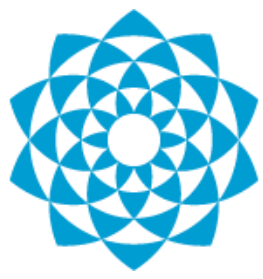
knowledge, skills and competences based on a continuously increasing level of complexity related to the learners' development.

Learn STEM is complex from the perspective of the learners' development since it seeks to empower learners to use their abilities, competences and (self-) reflective learning as a support for their emotional and social development. 


\subsection{Learn STEM is process-oriented}

Learn STEM is process-oriented in regards to the learning activities. Learners can explore STEM in a self-regulated and creative way through exploration and creation. In Learn STEM, processes are iterative, focusing on the learners' development but also train basic skills and build profound knowledge.

Learn STEM is an iterative learning process with continuous improvement of the learner's competences, skills and mental strategies. Learn STEM focusses on the following processes:

- Explore

- Build

- Reflect and

- Improve.

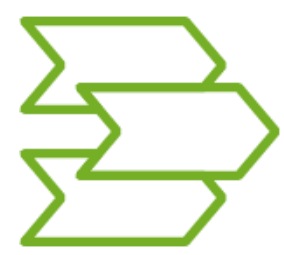

Most importantly, the iterative progress of the Learn STEM processes is flexible and allows for different pathways and options. This can be achieved by adjusting the curriculum applying defined and interconnected topics or following the principle of self-regulation by learners' themselves or in small working groups: learners can choose from different options either directly prepared and provided by the teacher or discussed during continuous reflection.

\subsection{Learn STEM is holistic}

Learn STEM is holistic in regards to the subjects, their connections and the methods to teach. Learn STEM focuses on understanding general ideas in STEM rather than accumulating specialised knowledge. Learn STEM emphasises the ethical component of STEM and contributes to the learners' personal development.

STEM influences the society in various ways and on different levels. Through Learn STEM, learners get introduced to these interactions and

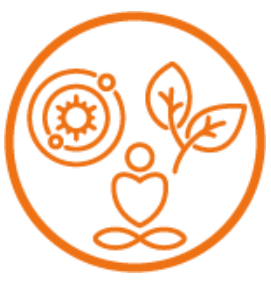
consequently the responsibility of scientists and engineers. STEM skills and competences built by the learner will in turn affect and serve the society. STEM learners, who choose to become scientists, engineers or entrepreneurs, may develop new technologies or discover new scientific phenomena which can change peoples' life.

Debates on ethical aspects of STEM developments may help to understand the rather complex mechanisms in the development of societies. Learn STEM connects STEM with social aspects as well as other areas of the humanities such as art. 


\subsection{Learn STEM is practical}

Learn STEM is practical in regards to the learning experiences and their applications. Learn STEM supports learners in gaining knowledge, acquiring skills and building competences through real-world experiences and observations. Learn STEM leads to action and (co-) creation with enthusiasm by creating and utilising motivation.

Learn STEM practice is embedded into an approach where learning arises from getting real-world lessons and learning by experiencing. Learners will be actively engaged and learn through co-creation with others.

An important aspect of practice is real-world contact, e.g., with business, research and industry. Impressions from the real-world can stimulate creativity and motivation. In addition, it offers the possibility to gain insights into potential professional careers and may encourage learners to start a vocational development in STEM topics including a university study. Besides companies, interactions with research institutions can provide a unique experience. Through interactions with students, an exclusive situation can be exploited since communication occurs featuring a rather small age difference.

\subsection{Learn STEM is social}

Learn STEM is a social activity with human interaction and emotional involvement. The learning process is learner-centered aiming to impact individuals and the society by association. Learn STEM is inclusive, gender balanced and values diversity.

Learn STEM is social in relation to the learning environment and the learning impact. It happens constantly; it is a social activity and facilitates relationships between the learner and other learners or stakeholders (such as teachers, coaches,

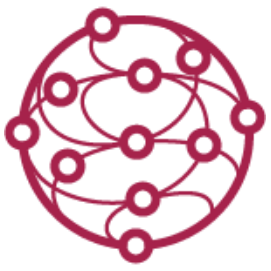
parents, experts). It also involves team work for problem solving. Thus, learning happens via social interactions within and outside of school. The intersubjectivity by discussing views among the different stakeholders helps learners to create new insights and meanings, increase motivation and enforces new knowledge exchange or even collaboration.

There is close interaction of the society with the STEM area. Social developments can stimulate science and technology to find proper solutions. But STEM also strongly influences the society by providing new technical or technological achievements which impact everyday life. An effective interaction between both - under consideration of environmental and global aspects - is essential and will impact the prosperity in the development. 


\section{Conclusions and outlook}

This article introduced the Mixed Methods research from an international research team that combined an in-depth literature review, three online surveys for teachers $(n=211)$, headmasters $(n=21)$ and learners $(\mathrm{n}=337)$. The first findings from the teachers' and headmasters' survey reveal a similar but differentiated view on the current STEM education. The feedback on the question concerning the usefulness of the pedagogical model Learn STEM was very positive by the teachers ( $74 \%$ fully agreed or agreed) and even better by the headmasters (92\% fully agreed or agreed).

Consequently, the international research team develops a teacher training programme and on online course to introduce and discuss innovative STEM education in schools based on the pedagogical model Learn STEM. The needs and preferences for (open) online education in schools and lifelong learning are identified and present diverse opportunities for the application in STEM education (Stracke et al., 2017). Key challenge is to meet and design the appropriate quality for (open) online education: Therefore, the design of the online course for the teacher training programme will benefit from the re-usage and adaptation of international standards such as first ISO norm for technology-enhanced learning ISO/IEC 40180 (2017) and QRF, the Quality Reference Framework for online education (Stracke et al., 2018). They were already consulted and applied for the presented holistic pedagogical model Learn STEM.

Future research is required to address the specific needs of teachers in schools for the direct implementation to facilitate pupil-centered STEM education that is following the five principles of the pedagogical model Learn STEM (complex, process-oriented, holistic, practical and social).

\section{Acknowledgment}

This article is supported by Learn STEM, the European Alliance for innovative STEM learning in schools (www.Learn-STEM.org). Main goal of Learn STEM is to improve the quality and efficiency of STEM learning in secondary schools through cross-disciplinary and reflective STEM education and pedagogical methodologies. Learn STEM is funded by the European Commission under the project number: 2017-1-NL01-KA201-035232.

\section{References}

Dewey, J. (1966). Democracy and Education: An Introduction to the Philosophy of Education. New York: The Free Press.

European Commission (2007): Science Education NOW. A Renewed Pedagogy for the Future of Europe [Rocard-Report]. Retrieved from: https://ec.europa.eu/research/sciencesociety/document_library/pdf_06/report-rocard-on-science-education_en.pdf

Harlen, W. (Ed.). (2015). Working with Big Ideas of Science Education. Trieste: Global Network of Science Academics (IAP) Science Education Programme. Retrieved from: www.ase.org.uk/bigideas

ISO/IEC 40180 (2017). Information Technology - Quality for Learning, Education, and Training - Fundamentals and Reference Framework. Geneva: International Organisation for Standardization (ISO). [developed by international standardization committee ISO/IEC JTC1 SC36] 
Organisation for Economic Co-operation and Development (2016). Education at a glance 2016: OECD indicators. Paris: OECD Publishing.

Piaget, J. (1953). The origin of intelligence in the child. London: Routledge.

Rousseau, J. J. (1968). The Social Contract. Harmondsworth: Penguin.

Stracke, C. M. (2019). Quality Frameworks and Learning Design for Open Education. The International Review of Research in Open and Distributed Learning, 20(2), 180-203. doi:10.19173/irrodl.v20i2.4213 [Open Access]

Stracke, C. M. (2014). How Innovations and Competence Development support Quality in Lifelong Learning. The International Journal for Innovation and Quality in Learning, 2(3), 35-44. [Open Access] Retrieved from http://www.opening-up.education

Stracke, C. M. (2012a). Competences and Skills for the challenges of the Digital Age: Combining Learning-Outcome Orientation with Competence Development and Modelling for Human Resources Development / ЗНАНИЯ И НАВЫКИ ДЛЯ РЕШЕНИЯ ПРОБЛЕМ ЦИФРОВОГО ВЕКА: СОЧЕТАНИЕ ОБУЧЕНИЯ КАК РЕЗУЛЬТАТ ОРИЕНТАЦИИ НА РАЗВИ-ТИЕ КОМПЕТЕНТНОСТИ И МОДЕЛИРОВАНИЕ РАЗВИТИЯ ЛЮДСКИХ РЕСУРСОВ. Информатизация образования и науки [= Информике (Informika), ISSN 2073-7572], 13(1), 146160. Retrieved from http://www.opening-up.education

Stracke, C. M. (2012b). Competences and skills for learning-outcome orientation: competence development, modelling, and standards for human resources development, education and training. 华东师范大学学报 (自然科学版) Journal of East China Normal University, 2(2012), 115-130. doi:10.3969/J.ISSN1000-5641.2012.02.012 [CLC number: Q948] Retrieved from http://www.opening-up.education

Stracke, C. M. (2011). Competences and skills in the digital age: Competence development, modelling, and standards for human resources development. In García-Barriocanal, E. et al. (Eds.), Communications in Computer and Information Science, vol. 240 [Proceedings of the Metadata and Semantic Research Conference]. Berlin/ Heidelberg: Springer. pp. 34-46. [ISBN: 978-3-642-24730-9] doi:10.1007/978-3-642-24731-6_4

Stracke, C. M., van Dijk, G., Daneniene, J., Kelmelyte, V., Lisdat, F., Wesolowski, A., Barreiros, A., Baltazar, R., Simoens, W., Desutter, J., Pascoal, A., Rimkeviče, A., Spatafora, M., Cotovanu, A. M., \& Spatafora, A. (2019). Learn STEM. The Pedagogical Model for Innovative STEM Learning and Teaching. Retrieved from http://www.Learn-STEM.org/Model [Open Access]

Stracke, C. M., Tan, E., Texeira, A., Pinto, M., Vassiliadis, B., Kameas, A., Sgouropoulou, C., \& Vidal, G. (2018). Quality Reference Framework (QRF) for the Quality of Massive Open Online Courses (MOOCs). Retrieved from http://www.mooc-quality.eu/QRF [Open Access]

Stracke, C. M., Kameas, A., Vassiliadis, B., Sgouropoulou, C., Texeira, A. M., Pinto, M., \& Vidal, G. (2017). The Quality of Open Online Education: Towards a Reference Framework for MOOCs. In Proceedings of 2017 IEEE Global Engineering Education Conference (EDUCON) (pp. 1712-1715). doi:10.1109/EDUCON.2017.7943080 Retrieved from http://www.opening-up.education

Vasquez, J. A. (2014). STEM Beyond the Acronym, Educational Leadership, 72, 4, p. 10, MAS Ultra - School Edition.

Vygotsky, L. (1988). Thought and Language. Cambridge, MA: MIT Press.

Weinert, F. E. (2001). Concept of competence: A conceptual clarification. In D. S. Rychen (Ed.), Defining and selecting key competencies (pp. 45-66). Seattle: Hogrefe \& Huber.

Westera, W. (2001). Competences in education: A confusion of tongues. Journal of Curriculum Studies, 33(1), 75-88. doi:10.1080/00220270120625

World Bank (2016). World development report 2016: Digital dividends. Washington, DC: World Bank. 